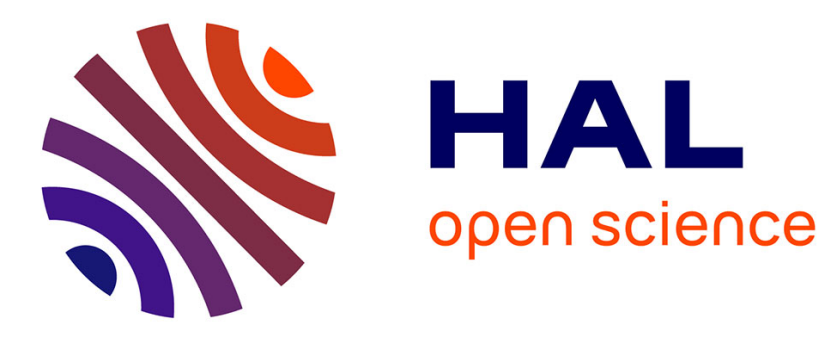

\title{
Detailed lithospheric structure of an arc-continent collision beneath Taiwan revealed by joint inversion of seismological and gravity data
}

Stephanie Gautier, Christel Tiberi, Marie Lopez, Océane Foix, Serge Lallemand, Thomas Theunissen, C. Hwang, E. Chang

\section{To cite this version:}

Stephanie Gautier, Christel Tiberi, Marie Lopez, Océane Foix, Serge Lallemand, et al.. Detailed lithospheric structure of an arc-continent collision beneath Taiwan revealed by joint inversion of seismological and gravity data. Geophysical Journal International, 2019, 218 (1), pp.586-600. 10.1093/gji/ggz159 . hal-02131923

\section{HAL Id: hal-02131923 \\ https://hal.umontpellier.fr/hal-02131923}

Submitted on 30 Jun 2020

HAL is a multi-disciplinary open access archive for the deposit and dissemination of scientific research documents, whether they are published or not. The documents may come from teaching and research institutions in France or abroad, or from public or private research centers.
L'archive ouverte pluridisciplinaire HAL, est destinée au dépôt et à la diffusion de documents scientifiques de niveau recherche, publiés ou non, émanant des établissements d'enseignement et de recherche français ou étrangers, des laboratoires publics ou privés. 
See discussions, stats, and author profiles for this publication at: https://www.researchgate.net/publication/333071914

\section{Detailed lithospheric structure of an arc-continent collision beneath Taiwan revealed by joint inversion of seismological and gravity data}

Article in Geophysical Journal International · March 2019

DOl: $10.1093 / \mathrm{gj} / \mathrm{ggz} 159$

\section{CITATIONS}

8 authors, including:

Stéphanie Gautier

Université de Montpellier

50 PUBLICATIONS 282 CITATIONS

SEE PROFILE

97. Marie Lopez

2 PUBLICATIONS OCITATIONS

SEE PROFILE

Some of the authors of this publication are also working on these related projects:

Subduction Interface Roughness and Megathrust Earthquakes View project

Deconvolution of acoustic signals in propagation problems View project

\section{READS}

89

Christel Tiberi

CNRS University of Montpellier

82 PUBLICATIONS 1,705 CITATIONS

SEE PROFILE

Océane Foix

Institut de Physique du Globe de Paris

5 PUBLICATIONS 0 CITATIONS

SEE PROFILE 


\title{
Detailed lithospheric structure of an arc-continent collision beneath Taiwan revealed by joint inversion of seismological and gravity data
}

\author{
S. Gautier, ${ }^{1}$ C. Tiberi, ${ }^{1}$ M. Lopez, ${ }^{1}$ O. Foix,${ }^{2}$ S. Lallemand, ${ }^{1}$ T. Theunissen ${ }^{\bullet}, 3$ \\ C. Hwang ${ }^{\oplus 4}$ and E. Chang ${ }^{5}$ \\ ${ }^{1}$ Géosciences Montpellier (GM), Université de Montpellier, CNRS, Université des Antilles, France.E-mail: stephanie.gautier-raux@umontpellier.fr \\ ${ }^{2}$ Département de sismologie, Institut de Physique du Globe de Paris, CNRS, Paris, France \\ ${ }^{3}$ Department of Earth Science, University of Bergen, Postboks 7803, N-5020 Bergen, Norway \\ ${ }^{4}$ Department of Civil Engineering, National Chiao Tung University, Hsinchu, Taiwan \\ ${ }^{5}$ Institute of Oceanography, National Taiwan University, Taipei, Taiwan
}

Accepted 2019 March 22. Received 2019 March 12; in original form 2018 December 21

\begin{abstract}
SUMMAR Y
The largest compilation of seismological and gravimetry data are combined in a sequential inversion to shed light on unresolved crustal structures in Northern Taiwan and Southernmost Ryukyu area. Our density and seismic velocity models reveal a NW-SE trending Transfer Zone (TZ) between $23.25^{\circ} \mathrm{N}$ and $24^{\circ} \mathrm{N}$. This primary TZ delimits major changes in the Eurasian Plate (EP) slab geometry and dynamics, as well as first order crustal structure variations. North of this TZ, the EP slab is breaking off from north to south as a result of (1) the extreme EP bending favouring plastic deformation, (2) the stretching of the plate caused by the downward pull of the oceanic part of the slab versus the buoyancy of continental part of the plate still deforming in the Taiwan orogen and (3) the indentation of the EP slab by the western slab edge of the Philippine Sea Plate (PSP).

The change of EP slab dip angle is clearly observed in the density profiles. The subvertical northernmost tip of EP slab allows asthenospheric upwelling through slab tear and subsequent invasion of the region beneath the Longitudinal Valley. This process is migrating southward up to the TZ, which marks the transition to a different rheological behaviour. The combination of deep arc-continent collision, clockwise asthenospheric toroidal flow and westward propagation of the southern Okinawa rift results in a $100^{\circ}$ clockwise rotation of the northernmost tip of the Central Range. The eastward extrusion of this crustal block ( $\sim 90 \mathrm{~km}$ in diameter) overlays and deflects the PSP slab.

The indentation of the EP by the PSP (Luzon Arc) thus results in complex lithospheric accommodation processes and structures.
\end{abstract}

Key words: Gravity anomalies and Earth structure; Joint inversion; Crustal imaging; Seismic tomography; Subduction zone processes.

\section{INTRODUCTION}

Seismicity and topography in a tectonically active region reflect the complex interaction between tectonics (fault activity, flexure, crustal and mantle flows) and surface processes. Geophysics offers ways to investigate the crustal or lithospheric structure in order to identify those processes and to determine their relationships. However, because of the sparse data coverage (both in space and time) or the parameter dependence to several factors, the obtained models are non-unique (Tarantola 2004). In order to reduce the model space solutions and better constrain the sources of crustal anomalies, one can use independent complementary data sets in a joint inversion scheme (e.g. Lines et al. 1988; Parsons et al. 2001;
Basuyau \& Tiberi 2011). This cooperative inversion procedure has long been proved, for several decades, to bring more constraints for geodynamical interpretations and to tackle tectonic questions in various environments (e.g. Lees \& VanDecar 1991; Julia et al. 2000; Tiberi et al. 2003; Roecker et al. 2004). We develop here a new sequential inversion for gravity and local tomography and apply it to the NE Taiwan area, where active deformation results from the interaction between two opposite-verging subductions and the related arc-continent collision environment.

The convergence between the Eurasian Plate (EP) and the Philippine Sea Plate (PSP) creates the Taiwan orogeny, and the associated complex deformation pattern at the surface. Although morphology of the PSP and EP has long been studied through local tomography 
(e.g. Wu et al. 2009; Theunissen et al. 2012b), their interaction and effect on crustal deformation under Taiwan Island remains a matter of debate, particularly as a result of the non-unique interpretation of seismic velocities (Chou et al. 2009; Huang et al. 2014a).

We take advantage of a recent gravity data compilation (Hwang et al. 2014) and a high-resolution local seismicity data set (modified from Theunissen et al. 2012b; Lallemand et al. 2013) to obtain a crustal image of coherent density and velocity contrasts at the southern termination of the Ryukyu Arc near Taiwan. Those two data sets cover offshore and onshore regions and offer a unique opportunity to widen the area of investigation compared to previous joint inversion studies (Masson et al. 2012; Li et al. 2014). Our new model helps to probe the interaction between the PSP and the EP and to constrain the 3 -D structural model of this complex geodynamical area.

In this study, we jointly inverted the two data sets to obtain quantitatively related 3-D velocity and density models fitting both sets of observations. This coherence helps us to discriminate between alternative natures of processes involved in the kinematics and deformation of NE Taiwan Island. We discuss the resulting well-resolved images in the frame of regional tectonics. We particularly enlighten the change of the EP slab dip angle, its tearing, and the role of a NW-SE trending Transfer Zone (TZ) beneath Taiwan.

\section{GEODYNAMICAL SETTING}

Taiwan orogen results from the oblique collision of the Luzon volcanic arc (LVA) with the Chinese continental margin (e.g. Suppe 1984; Angelier 1986) (Fig. 1). The LVA ceased to be active south of Taiwan, as the forearc basement was underthrusted beneath the arc in response to the increasing compression between converging plates (Chemenda et al. 2001; Malavieille et al. 2002). The LVA is carried by the PSP, which subducts northward beneath the southernmost Ryukyu Arc. The western edge of the Philippine Sea slab can be traced beneath northeastern Taiwan at least down to a depth of $250 \mathrm{~km}$, based on intraslab seismicity (e.g. Wu et al. 2009). The 8-9 $\mathrm{cm} \mathrm{yr}^{-1}$ of convergence between the PSP and the EP are entirely accommodated along the Manila Trench southwest of Taiwan, and along the Ryukyu Trench east of Taiwan. In between these two orthogonal subduction zones, the convergence is distributed over several lithospheric thrusts, the major one being the Longitudinal Valley Fault (LVF) separating the Central Range (CR) of Taiwan from the Coastal Range (Fig. 1). Another one develops offshore at the foot of the LVA slope off Hualien and propagates to the south off Taitung (Malavieille et al. 2002; Lallemand et al. 2013). As a result of the trending and vergence of both subductions zones $(\mathrm{N}-$ $\mathrm{S} \&$ east vergent and $\mathrm{E}-\mathrm{W} \&$ north vergent) with respect to the oblique convergence direction (NW-SE), the collision between the LVA and the Chinese platform started in the north about 3-5 Ma and propagated to the south (Suppe 1984; Malavieille et al. 2002). Today, the collision is paroxysmal in the middle of the island, where the extinct LVA forms the Coastal Range, as attested by the height culmination of the orogeny (Fig. 1). The LVA acts as an indenter or a buttress south of Hualien (Lu \& Malavieille 1994). As it disappears northward beneath northeast Taiwan, the stress regime changed from compression to extension and the oldest part of the orogen collapses (Lallemand \& Tsien 1997). The southern Okinawa rift developed synchronously with the westward propagation of the southern Ryukyu Trench (Lallemand et al. 2001a). The Ryukyu arc sliver thus moved south since 2-3 Ma, as the southern Okinawa Trough widened (Sibuet et al. 1998). The rift propagated at an angle into the Taiwan orogen facilitating the clockwise rotation of the northernmost Central Range (Rau et al. 2008). Finally, both the subducting, and colliding, PSP and the overriding EP severely deformed but the precise geometry of the converging plates imbrication is still unknown.

\section{DATA AND METHOD}

\subsection{Seismological data}

The seismic network is composed of 134 short period stations distributed between $120.8^{\circ} \mathrm{E}$ and $124.4^{\circ} \mathrm{E}$ of longitude and $22^{\circ} \mathrm{N}$ and $25.3^{\circ} \mathrm{N}$ of latitude (Fig. 2a). Records from 1974 to 2014 for stations belonging to CWB (Central Weather Bureau of Taiwan), JMA (Japan Meteorological Agency) and RATS campaign (Theunissen et al. 2012a,b) networks now supply the largest compilation of seismological data in Taiwan encompassing 520123 earthquakes with Mw magnitude in the range 2-7.6.

Among this huge database, we restricted our selection to events recorded after 1993 by the newer and more consistent CWB network for the Taiwan region. We selected events with a minimum of $8 P$-wave picking phases and $2 S$-wave ones according the three networks. The azimuthal gap should be less than $300^{\circ}$, the epicentral distance was restricted to $0-150 \mathrm{~km}$ range, and the depth limit was set to $150 \mathrm{~km}$. Those criteria led to a catalogue of 153120 earthquakes including $2603631 P$-wave and $2075319 S$-wave arrival times.

In a first step, we precisely relocated those events using a $1 \times 1 \times 1$ $\mathrm{km}^{3} P$ - and $S$-wave velocity model extending $370 \mathrm{~km}$ north from $22^{\circ} \mathrm{N}$, and $350 \mathrm{~km}$ east from $120.9^{\circ} \mathrm{E}$. The a priori $P$-velocity model is extrapolated from Theunissen et al. (2012b). The corresponding initial $S$-velocity model is directly obtained from the $P$-velocity distribution assuming a $V_{P} / V_{S}$ ratio of 1.75 deduced from a Wadati diagram. We used the Non-Linear-Location software (NLLoc, Lomax et al. 2000) to absolutely relocate our catalogue earthquakes in this fine velocity model. Traveltimes between stations and nodes are computed using the Eikonal finite difference equation (Podvin \& Lecomte 1991), and the earthquake location is searched using the Oct-Tree method (Lomax et al. 2000).

Over the 153120 relocated earthquakes in this 3-D velocity model, we finally selected the 34080 best localized ones based on error-ellipses and residuals produced by NLLoc software, while maintaining a good spatial coverage (Fig. 2a). It results in 910941 $P$-wave and $675310 S$-wave arrival times.

\subsection{Gravity data}

Gravity data set is taken from Hwang et al. (2014) and combines land, airborne and shipborne data between $119^{\circ}$ and $123^{\circ}$ of longitude, $21^{\circ}$ and $26^{\circ}$ of latitude. Those three types of gravity data were assembled into a coherent data set to obtain a final $1^{\prime}$ gridded complete Bouguer anomaly [CBA, see Hwang et al. (2014) for data treatment].

Because the shortest wavelengths of CBA correspond to the uppermost crustal structures, which are not sampled by seismic stations, we filter the CBA with a low-pass Butterworth filter at $25 \mathrm{~km}$, which corresponds to the mean seismic station spacing (Fig. 2b). The resulting CBA was then decimated to $2^{\prime}$ in order to reduce the computing time without depreciating the velocity-density coherency. The final gravity database gathers 18271 points. Because the gravity data set does not cover the exact same area as seismic 


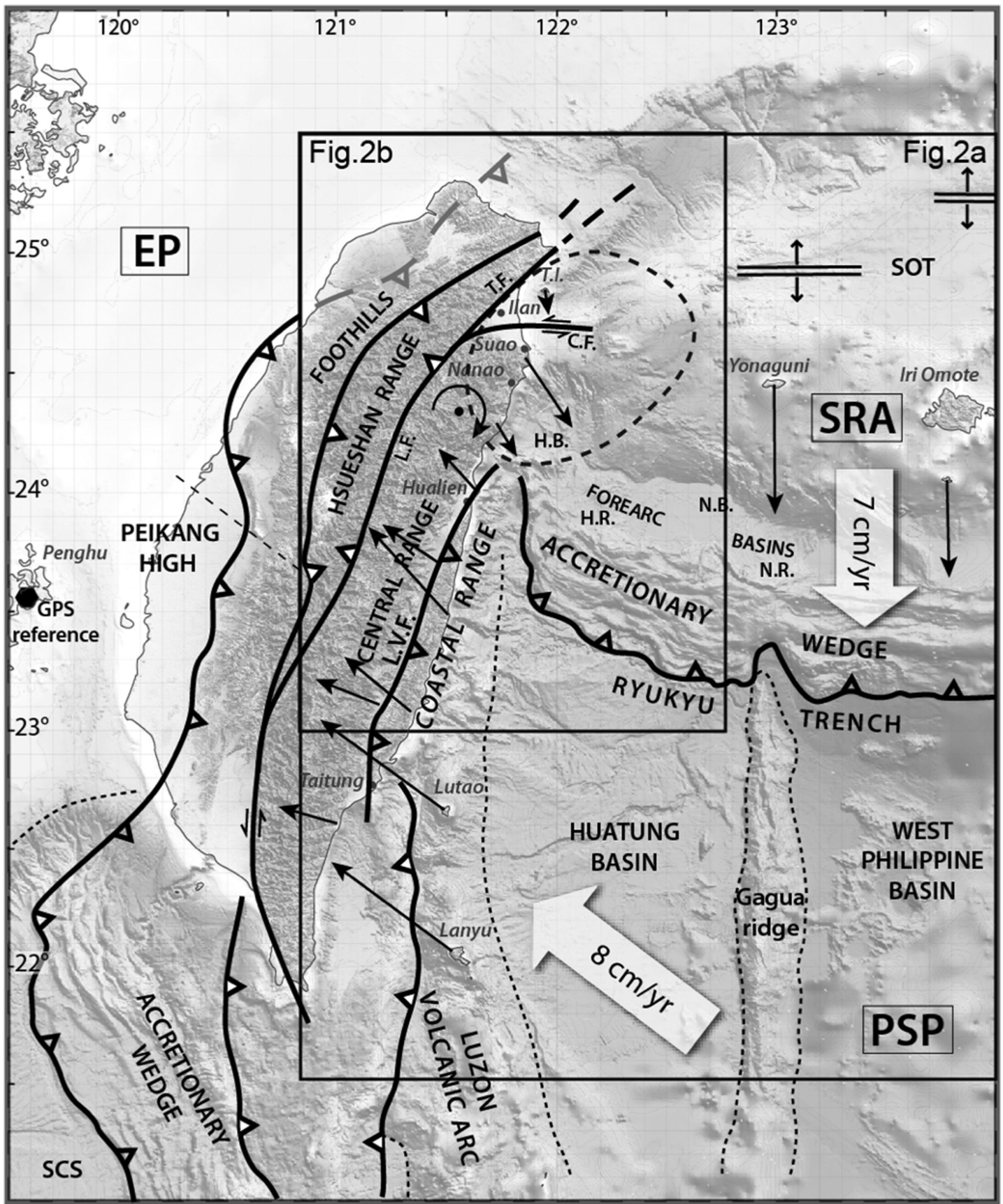

Figure 1. Structural and kinematic framework of the study area (EP, European Plate; PSP, Philippine Sea Plate; SRA, Southern Ryukyu Arc). Major structural units and places used in the text: CF, Choshui Fault; HB, Hoping Basin; HR, Hoping Rise; NB, Nanao Basin; TF, Toucheng Fault; TI, Turtle Island; LF, Lishan Fault. Black rectangles delimit the boundaries for Fig. 2.

data (Fig. 2), and to preserve the consistency of the cooperative method, we restricted our gravity zone to the common well resolved area: $23^{\circ} \mathrm{N}-25.5^{\circ} \mathrm{N}$ in latitude and $120.8^{\circ} \mathrm{E}-123.0^{\circ} \mathrm{E}$ in longitude. We finally invert 5106 gravity data in total.

The gravity data have already been extensively described and first analysed in Hwang et al. (2014). The CBA shows huge contrasting values between -80 and $+400 \mathrm{mGal}$. The highest values correspond to the oceanic crust west of the Manila trench, to the Huatung basin east of the Luzon Arc and south the Ryukyu trench, and the central part of the Southern Okinawa Trough. The Longitudinal Valley Fault (LVF) and the Coastal Range are marked by a relative high in the CBA (+60 mGal). The lowest values coincide with the Hsuehshan
Range of Taiwan ( $-80 \mathrm{mGal})$. Laterally, the Hoping Basin and the Ilan Plain are also associated with a negative CBA $(-50 \mathrm{mGal})$ off the northeastern part of Taiwan.

\section{METHOD}

Local seismicity traveltime inversion is highly non-linear, because it simultaneously inverts for velocity, hypocentres and origin time (Pavlis \& Booker 1983; Nolet \& Moser 1993). When the local seismic data is combined with gravity in a joint scheme, the nonlinearity increases and requires additional smoothing ad hoc constraints (Parsons et al. 2001; Vernant et al. 2002; Li et al. 2014). In 

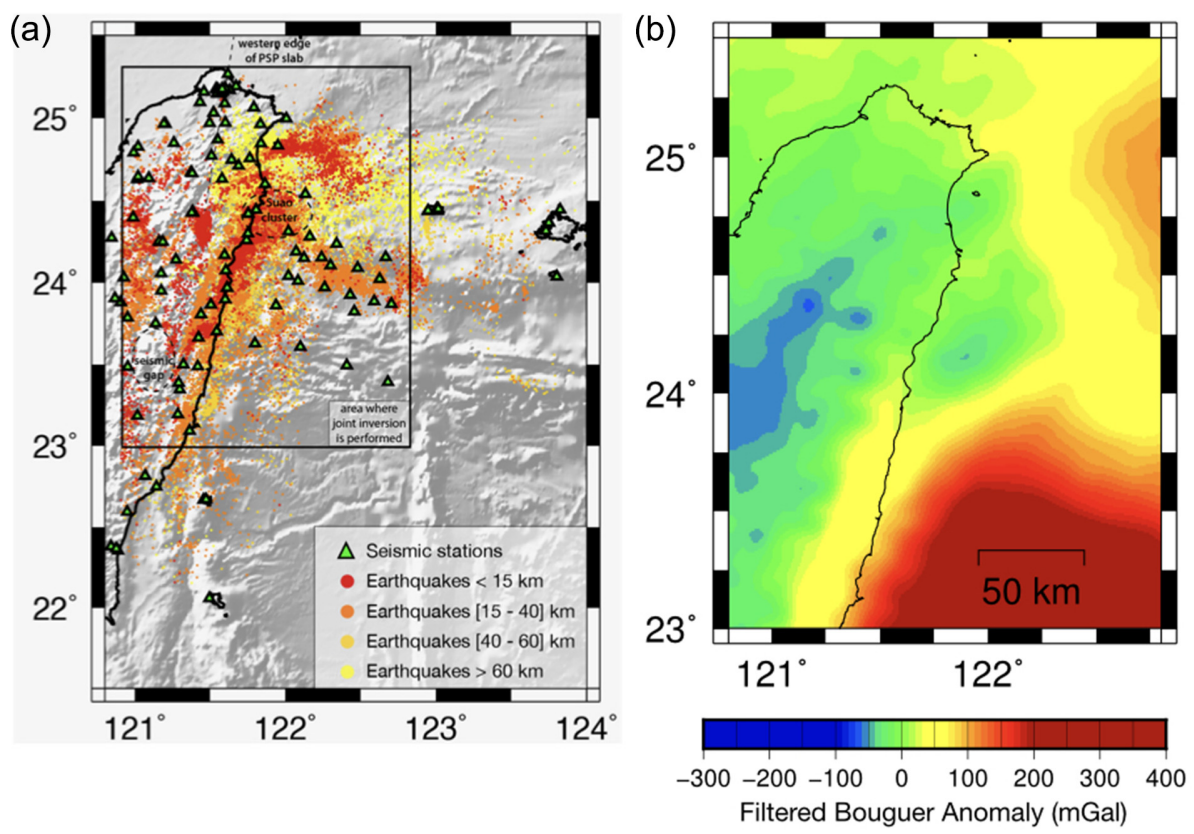

Figure 2. (a) Seismicity map showing the $34080 M>4$ selected events used in this study and relocated in a 3-D velocity model, with the seismic stations (triangles) used for the tomography. (b) Complete Bouguer gravity data (filtered for wavelength $>25 \mathrm{~km}$ ) used in the sequential inversion.

order to limit the use of arbitrary factors in the inversion process, we do not consider hypocentre relocation and invert for velocity and density contrasts only. We use previously relocated events (see Section 3.1). Finally and following Masson et al. (2012), we adopt a sequential scheme to stabilize the inversion process and to iteratively converge towards a common velocity and density solution.

\subsection{Tomographic inversion process}

We use the linearized delayed traveltime tomography method described in Gautier et al. (2006, 2008) and Priolo et al. (2012) that originally inverts the velocity distribution and the hypocentre parameters simultaneously. Normalization or scaling of the derivative matrix is performed for better reconstruction of the different parameters. This operation removes influences of the different parameters and takes into account the sensitivity of the data to each class of parameters. This inversion method provides a smooth velocity model estimated on a 3-D, regularly spaced, rectangular grid. The inversion is based on a least square process using the LSQR method (Paige $\&$ Saunders 1982). The travel-times are first estimated through a wavefront calculus on a fine grid (Podvin \& Lecomte 1991) and are then a posteriori re-evaluated along each ray path using a time gradient approach. The inversion process is iterative and updates the 3-D velocity distribution at each iteration.

Following synthetic tests using the real event-station geometry we fix both the grid spacing and the parametrization of the inversion to optimize the resolution. Finally, the velocity model is composed of $37 \times 38 \times 55$ nodes in EW, NS and vertical directions respectively. The node spacing is $10 \mathrm{~km}$ in horizontal and $3 \mathrm{~km}$ in vertical in order to optimize the station spacing that ranges between 5 and $20 \mathrm{~km}$. The velocity starting model is extrapolated from Theunissen et al. (2012b) in order to ensure a rapid and adapted convergence of the inversion (Kissling et al. 1994). The scaling factor was set to 1 for $P$ wave, 2 for $S$ wave and 0 for both the location and the origin time of earthquakes in order to only consider the velocity distributions in the inversion process. We set the damping values to 0.4 and 0.8 for $P$ and $S$ wave, respectively. We applied no smoothing constraint. We check the good convergence and result of the inversion through the final rms decrease.

\subsection{Gravity inversion process}

The gravity inversion follows the technique of Widiwijayanti et al. (2004). The method is extracted from the joint inversion iterative scheme of Tiberi et al. (2003) and extensively described there. The direct problem is solved following the formulation of Blakely (1995) and the inversion is performed by weighted damped least square solution. The convergence of the gravity inversion is controlled through the decrease of the RMS. As the gravity inversion problem is very linear (Blakely 1995), the RMS misfit reaches a minimum value after only two iterations. The density model is divided in $22 \times 27 \times 20$ parallelepipedic blocks in $X, Y, Z$ (east, north, vertical) directions, respectively. The boundary effects are absorbed by one additional block in $X$ - and $Y$-axes on each edge of the 3-D model. Each density block corresponds to one velocity node in order to respect full cooperative process. The maximum depth of cooperative inversion is $60 \mathrm{~km}$, assuming that deeper bodies will result in longer wavelength and smaller amplitude than those actually present in the gravity signal.

\subsection{Density-velocity relationship}

The sequential inversion requires a mathematical link between velocity and density. Various empirical laws exist depending on rock type, composition and considered depth (e.g. Nafe \& Drake 1963; Christensen 1996). However, the initial Birch's Law (1961) seems to be a general good approximation. The widespread success of it is due to its linear approximation of a power law derived from lattice dynamics over the density range [2.5-4.0], within which our model densities vary (Chung 1972). We tested three different relationships previously used in similar contexts (Masson et al. 2012; Li et al. 

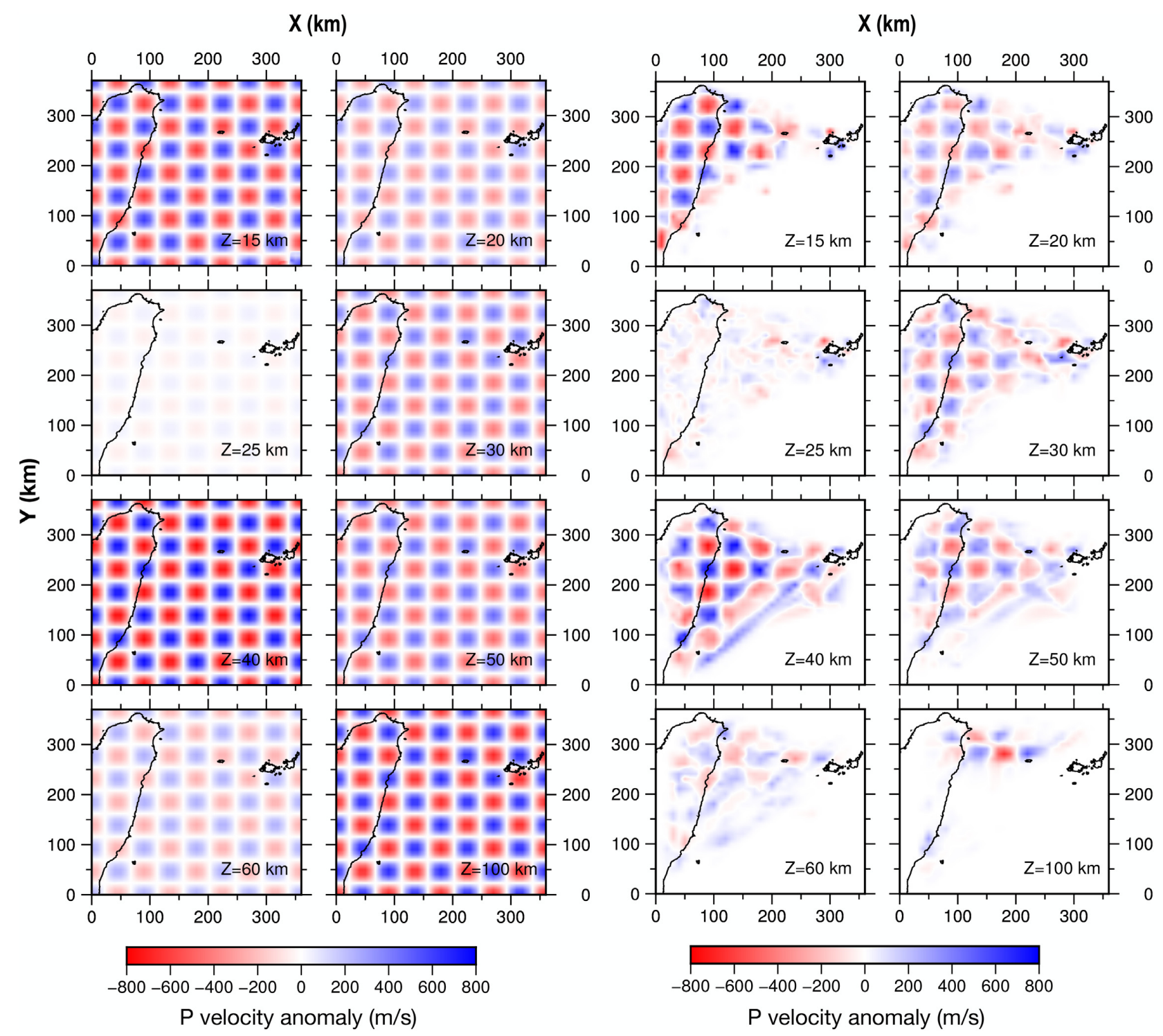

Figure 3. Representative results of the checkerboard tests for the velocity model. The left-hand panel indicates the true checkerboard anomaly added to the 3-D final velocity model and the retrieved patterns after tomographic inversion are shown on the right-hand side. The irregular shape of the retrieved checkerboard pattern accounts for the ray distribution (see text for details).

2014; Lo et al. 2018): a Gardner's type $\left(\rho=0.31 V p^{0.25}\right)$, Christensen's type ( $\rho=0.2891 . V p+0.9893)$ and Birch's type $(V p=2.5$ $\rho-1.67)$. Our preferred solution is obtained with the last equation, for which the lowest global RMS and difference with the velocity model are reached during the joint inversion process. Besides, this relationship gives the most realistic density and velocity values.

\subsection{Sequential inversion process}

The sequential inversion scheme consists of running successive tomographic and gravity inversions. Birch's law guarantees the coherency between the velocity and density models. Because this relationship implies only $P$-wave velocity, we will only consider hereafter the $P$-velocity model in the tomographic process, even if $S$-wave velocity perturbations are also inverted during the tomographic loop.

We start with a tomographic inversion that leads to a $3-\mathrm{D}$ velocity model. The $P$-velocity model is turned into a $3-\mathrm{D}$ density distribution via Birch's law, which we insert as an initial constraint for a gravity inversion. This second inversion gives an updated density model that we transform into a new $P$-velocity model through the Birch's law. This new 3-D $P$-velocity model can then be in turn used as a starting model for a new tomographic inversion, making a loop in our sequential inversion. The following loops used the same process, that is using the final velocity model from tomographic inversion as a starting model for the gravity inversion.

The sequential process is stopped when the difference between observed and calculated data (RMS) converges towards a stable value.

\subsection{Joint inversion convergence and resolution}

We first perform a delay-time inversion alone and we compare the results with a real sequential delay-time/gravity inversion. Those two 


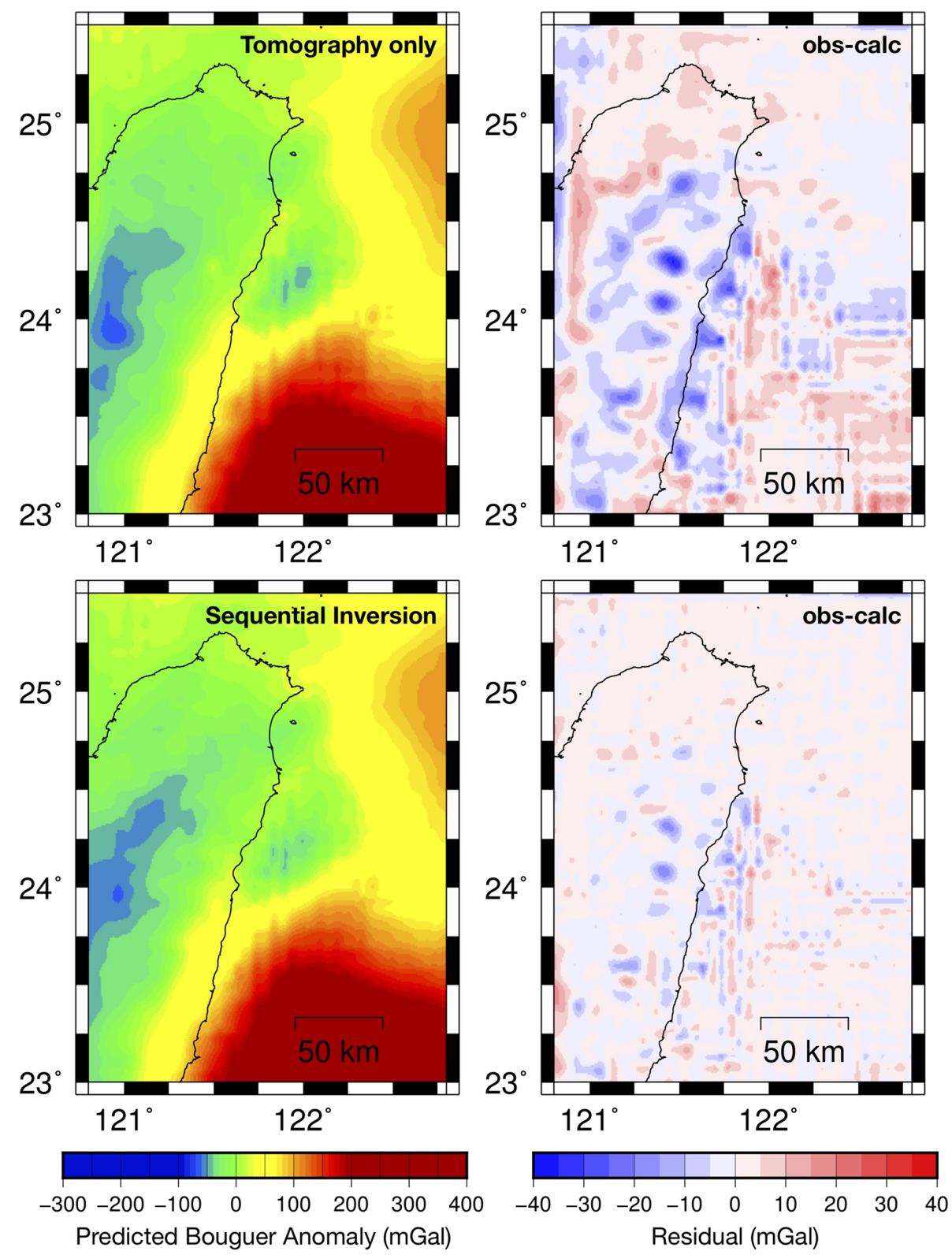

Figure 4. Calculated gravity anomaly for tomography inversion only (top panel), and after five loops of sequential inversion (bottom panel). The gravity residuals relative to the observed Bouguer anomaly are displayed on the right part for each case.

independent inversions have the same parametrization (i.e. starting model, grid parametrization, damping and smoothing) to be fully comparable. In both schemes, no significant residual variance reduction was achieved after 16 iterations for the delay-time inversion, and five loops for the sequential inversion $(<0.1$ per cent). For the delay-time inversion only, the RMS of arrival-time residuals decreases from 0.54 to $0.305 \mathrm{~s}$. The final calculated model corresponds to a gravity RMS of $64.9 \mathrm{mGal}$. For the sequential joint inversion scheme, the RMS decreases from 0.54 to $0.29 \mathrm{~s}$ for the arrival-time residuals, and from $64.9 \mathrm{mGal}$ down to $5.0 \mathrm{mGal}$ for the gravity residuals. The similarity in misfit value is most likely coming from the use of the 3-D initial extrapolated velocity model of Theunissen et al. (2012b), which highly constrains the resulting models, in particular in areas with dense ray coverage.

Before discussing the results, we investigated the resolving power of the inversions. The resolution of the gravity signal is quite easy to estimate as data with a good accuracy are evenly distributed over the study area. In contrast, the velocity image resolution is highly dependent on the stations-sources distribution. To assess the resolution of final velocity model, we performed checkerboard tests on final tomographic data using the real events and stations distribution. Checkerboard test is an a posteriori procedure that provides a global and quick insight of the local resolution length by looking at the smearing of the velocity patterns. This procedure requires first a reference model obtained by adding a velocity perturbation to the final tomographic model. This velocity perturbation is strong compared to the numerical noise level and yet small enough to avoid noticeable disturbances in the ray coverage. Traveltimes are computed in the reference model and a noise term is added to this synthetic data set from a uniform distribution between -0.05 and $0.05 \mathrm{~s}$. This simulates errors in the arrival times such as for example picking errors. The resulting synthetic data set is then inverted using 

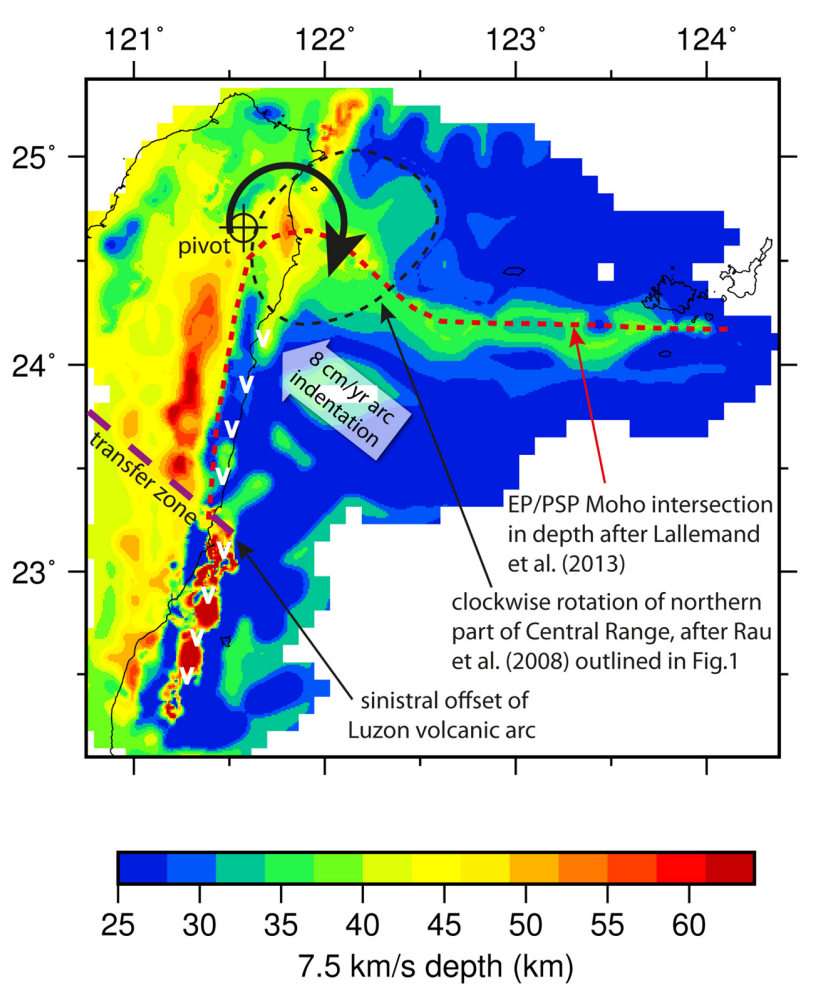

Figure 5. Moho depth map of the studied area deduced from the $P$-velocity model for $V_{p}$ equal to $7.5 \mathrm{~km} \mathrm{~s}^{-1}$. Some geodynamic information used in the text for interpretation are also reported (V shapes represent the Luzon Arc unit, the red dashed line is the EP/PSP Moho intersection after Lallemand et al. (2013), the black dashed line circles the thickened crustal EP part overriding the PSP). The black arrow indicates the clockwise rotation of the central range around the pivot.

the same procedure and parametrization that was used for the real data. The final tomographic model is used as the input model in the inversion process. The recovered velocity pattern is then compared to this input model in order to estimate the model resolution for some parameters like the amplitude, the location, the size and the shape of the reconstructed anomalies.

We performed several checkerboard tests for input anomalies $\left(800 \mathrm{~km} \mathrm{~s}^{-1}\right.$ for $V p$ and $470 \mathrm{~km} \mathrm{~s}^{-1}$ for $\left.V s\right)$ of different sizes and locations. The smaller well-reconstructed pattern anomaly corresponds to $40 \times 40 \times 30 \mathrm{~km}^{3}$. This anomaly size defines the minimum anomaly size that is expected to be resolved in tomographic inversions. The pattern and amplitude of the input anomalies are well retrieved in areas with enough ray crossing (Fig. 3). The resolution decays with depth, and there is a loss of resolution after $50 \mathrm{~km}$, reflecting the depth distribution of seismic events. At $100 \mathrm{~km}$ depth, the resolution is limited to the Ryukyu arc-backarc transition, with still a good, but local, recovery of the geometry and the amplitude. The central part of Taiwan is well resolved until 40-50 km depth, and despite some smearing effects along the source-station direction in NE of Taiwan, the input anomaly are correctly estimated for the crustal depth.

\section{RESULTS}

Our results indicate that a single Birch's law for the whole volume of the model can satisfactorily explain the data with a good RMS decrease ( 55 per cent for the arrival time residuals and 92 per cent for gravity), and provides a calculated gravity anomaly very close to the observed one (Fig. 4). This underlines that the relationship between velocity and density can be approximated by a linear law without too much discrepancy, even if composition or temperature lateral effects can produce local fluctuations for the law. The sequential aspect of our inversion allows the density and velocity to depart from this simple linear relationship, and likely absorbs lateral or regional variations.

While the main features of the $P$-velocity model remain similar to those observed in the model generated by inversion of arrival times only and the model generated from the joint inversion, the gravity residuals are greatly improved, particularly in the central domain in Taiwan and along the eastern coast of the island (Fig. 4). However, gravity data also provide additional constraints on the velocity model in areas with poor ray path coverage and contribute to the refinement of the tomographic images elsewhere. This addition of information is also crucial for the output model and the consistency of the two datasets in the joint inversion procedure. By taking advantage of different data sensitivities and coverage, the joint inversion procedure improves the resolution of the different geophysical anomalies, both in amplitude and position.

Combining the new gravity data compilation and a complete seismic events catalogue allows us to first enclose a broader area in the Ryukyu zone than previous joint studies (Roecker et al. 2004; Masson et al. 2012; Li et al. 2014). Secondly, the 3-D Vp model from our inversion largely agrees with previous tomographic surveys in the region (e.g. Wu et al. 2007, 2009; Huang et al. 2014b). In particular, the overall Moho variation beneath the region (inferred from the $7.5 \mathrm{~km} \mathrm{~s}^{-1} P$-wave contour, Fig. 5) is very coherent with previous estimates (Kuo-Chen et al. 2012; Li et al. 2014). The thickening of the crust beneath the Central Range is particularly well imaged and reaches a maximum value of 55-60 km. The apparent thicker crust following the Ryukyu arc slope coincides well with the intersection between the EP Moho and the PSP Moho (Fig. 5, Lallemand et al. 2013). The sharp and narrow velocity increase near the eastern coast is also a common feature imaged in all recent tomographic studies (Wu et al. 2009; Kuo-Chen et al. 2012; Theunissen et al. 2012b; Huang et al. 2014a), and will be discussed in the following sections. We attribute small differences in shape and amplitude compared with previous models to the disparity of the datasets and the data treatment. In our case, the addition of gravity and supplementary seismic data offers us the opportunity to better detail the Moho deflection and the short wavelength variations in lithospheric structures.

A sharp change in the Moho depth is clearly evidenced between $23.25^{\circ} \mathrm{N}$ and $23.75^{\circ} \mathrm{N}$ (Fig. 5), which offsets main velocity and density anomalies (Figs 6-8). Offshore, south of this transition zone, the deepest Moho ( $>55 \mathrm{~km}$ ) corresponds to a NNE-SSW low density and velocity zone $\left(-0.25 \mathrm{~g} \mathrm{~cm}^{-3}\right.$ and $6.4 \mathrm{~km} \mathrm{~s}^{-1}$, respectively) (Figs 6-8, see V label). We relate this anomaly to the Luzon Arc structure, which has been previously evidenced in many geophysical studies (e.g. Lallemand et al. 2013; Huang et al. 2014b). The offset of Luzon volcanic arc north of $23.25^{\circ} \mathrm{N}$ (Fig. 5, see V labels) points out its probable segmentation as first proposed by Malavieille et al. (2002) and further imaged by Lallemand et al. (2013).

South of latitude $23.5^{\circ} \mathrm{N}$ and west of the Luzon Arc, the Moho is locally shallowing $(25 \mathrm{~km})$ along a NNE-SSW direction as previously observed by many authors (Kim et al. 2005, 2006; Kuo-Chen et al. 2012; Theunissen et al. 2012b). Between 25 and $35 \mathrm{~km}$ depth, our study associates this structure with high velocity $\left(7.2 \mathrm{~km} \mathrm{~s}^{-1}\right)$ and high density $\left(+0.3 \mathrm{~g} \mathrm{~cm}^{-3}\right)$ contrast, compatible with mantle densities (Figs 6-8, see HVHD label). This elongated high velocity anomaly expands north of $23.5^{\circ} \mathrm{N}$ up to $24.5^{\circ} \mathrm{N}$, while the density 

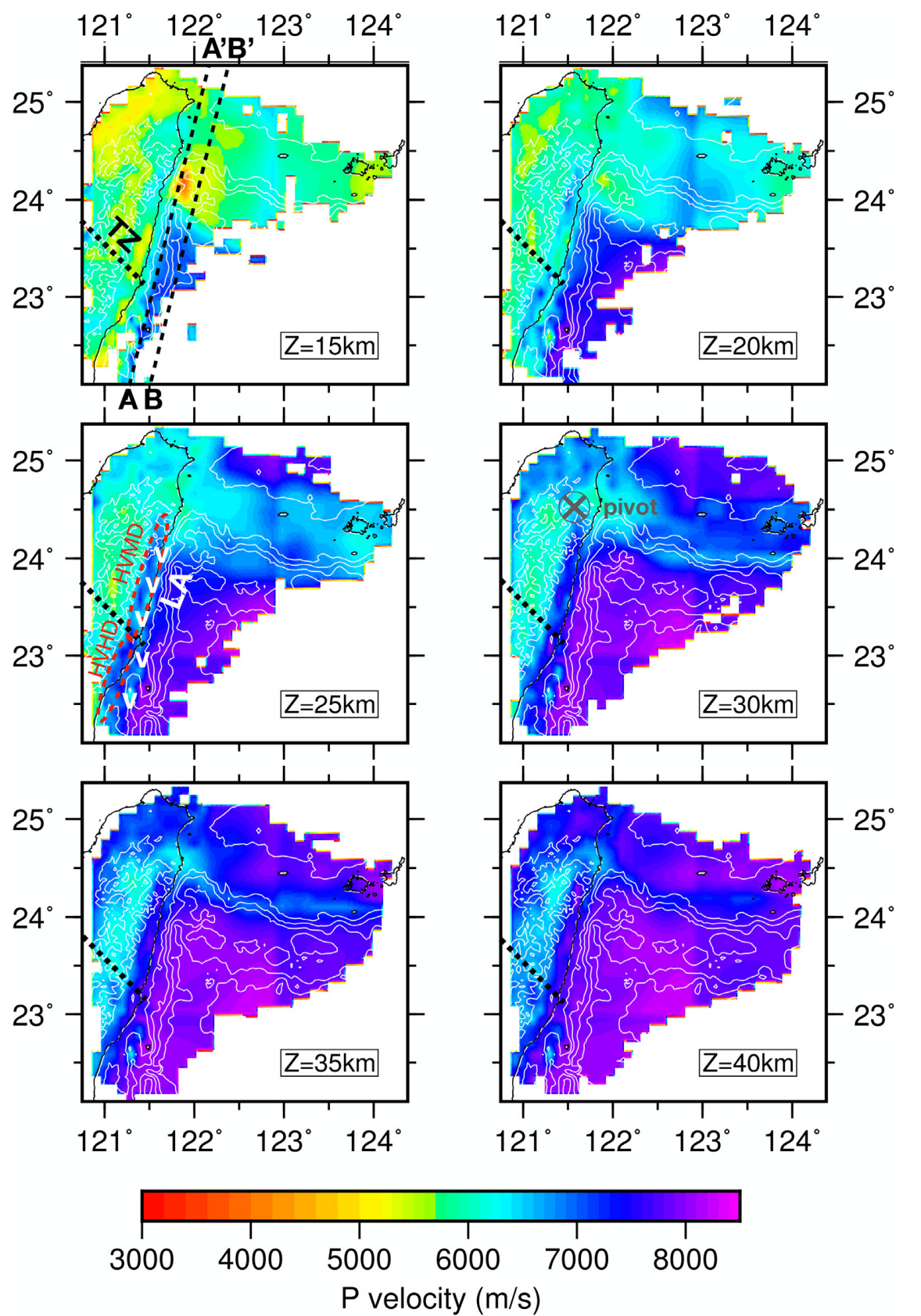

Figure 6. $V p$ model resulting from the sequential joint inversion for six different depths. Topography and bathymetry isolines are indicated in continuous white lines (isocontour every $1000 \mathrm{~m}$ from ETOPO2). The transfer zone TZ is highlighted with the thick dashed black line on all depths. White V symbols at $25 \mathrm{~km}$ outline the Luzon Arc unit. Patterns discussed in the text (HVMD and HVHD) are circled at $Z=25 \mathrm{~km}$. The pivot location is symbolized by the circled $X$ at the $30 \mathrm{~km}$ depth slice. AA' and BB' cross-sections directions are indicated on the first slice.

variation decreases down to $0.1 \mathrm{~g} \mathrm{~cm}^{-3}$ (Figs 6-8, see HVMD label). This contrast in physical parameters implies a change in the nature of the associated structure.

North of Hoping Basin, at $\sim 24.5^{\circ} \mathrm{N}$, a low velocity $\left(6.3 \mathrm{~km} \mathrm{~s}^{-1}\right)$ low density $\left(-0.3 \mathrm{~g} \mathrm{~cm}^{-3}\right)$ structure is well imaged from $25 \mathrm{~km}$ down to $40 \mathrm{~km}$ depth. Between $121.5^{\circ} \mathrm{E}$ and $122.5^{\circ} \mathrm{E}$, this anomaly overlays clear changes in the seismicity distribution at around $50 \mathrm{~km}$ depth (Fig. 9). As previously imaged by Wu et al. (2009), the slab dip angle becomes steeper. Additionally, our relocations enlighten a deflection in the Benioff zone as well as a double seismic zone in the depth range of $40-80 \mathrm{~km}$, as first described in NE of
Taiwan by Kao and Rao (1999). They explained this deformation by a lateral compression related to the oblique subduction. This anomalous zone exhibits velocity and density values similar to the Coastal Range ones at the same depths and seems only separated from it by the northern end of the NNE-SSW high velocity previously mentioned (Figs 6 and 7, HVMD label). This transition happens at $24.6^{\circ} \mathrm{N}$ and $121.6^{\circ} \mathrm{E}$ where the Moho locally thins (Fig. 5, pivot label).

Finally, the narrow NNE-SSW-trending crustal thick zone northeast of Ilan (Fig. 5) probably attests for the northern continuation of the Hsuehshan Range (Fig. 1). 

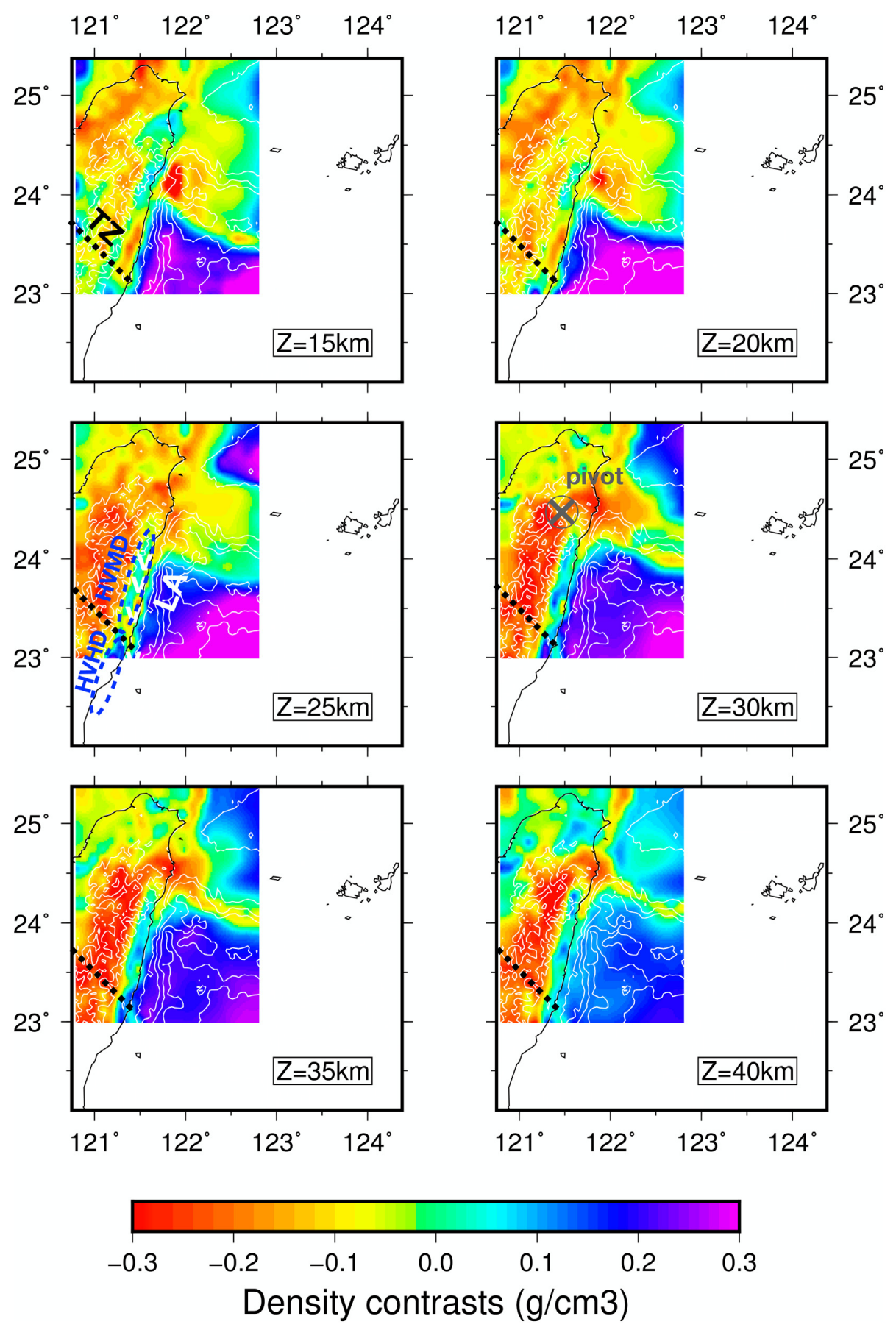

Figure 7. Density contrast model resulting from the sequential joint inversion for six different depths. Topography and bathymetry isolines are indicated in continuous white lines (isocontour every $1000 \mathrm{~m}$ from ETOPO2). The annotations are the same than for Fig. 6.

\section{DISCUSSION}

\subsection{Deep interaction between the Luzon Arc and the EP slab}

The Moho deepening corresponding to the Luzon Arc location south of $23.25^{\circ} \mathrm{N}$ (Figs 5-8) is greater than the previous studies in this area (Kuo-Chen et al. 2012; Li et al. 2014). We explain this overestimate through two limitations. First, the velocity amplitudes are clearly underestimated in this zone, as stated by the checkerboard tests (Fig. 3). Secondly, the gravity coverage does not allow overcoming this problem, as we are at the edge of the zone. However we can not exclude the effect of crustal overthickening due to the underthrusting of the Luzon forearc beneath the arc (Chemenda et al. 2001; Malavieille et al. 2002).

We interpret the adjacent high velocity high density body (Figs 68 , HVHD label) located at $25-40 \mathrm{~km}$ depth west of the LA as a local mantle pinch due to the PSP convergence. A part of the forearc mantle might have been trapped between the thicker continental EP 

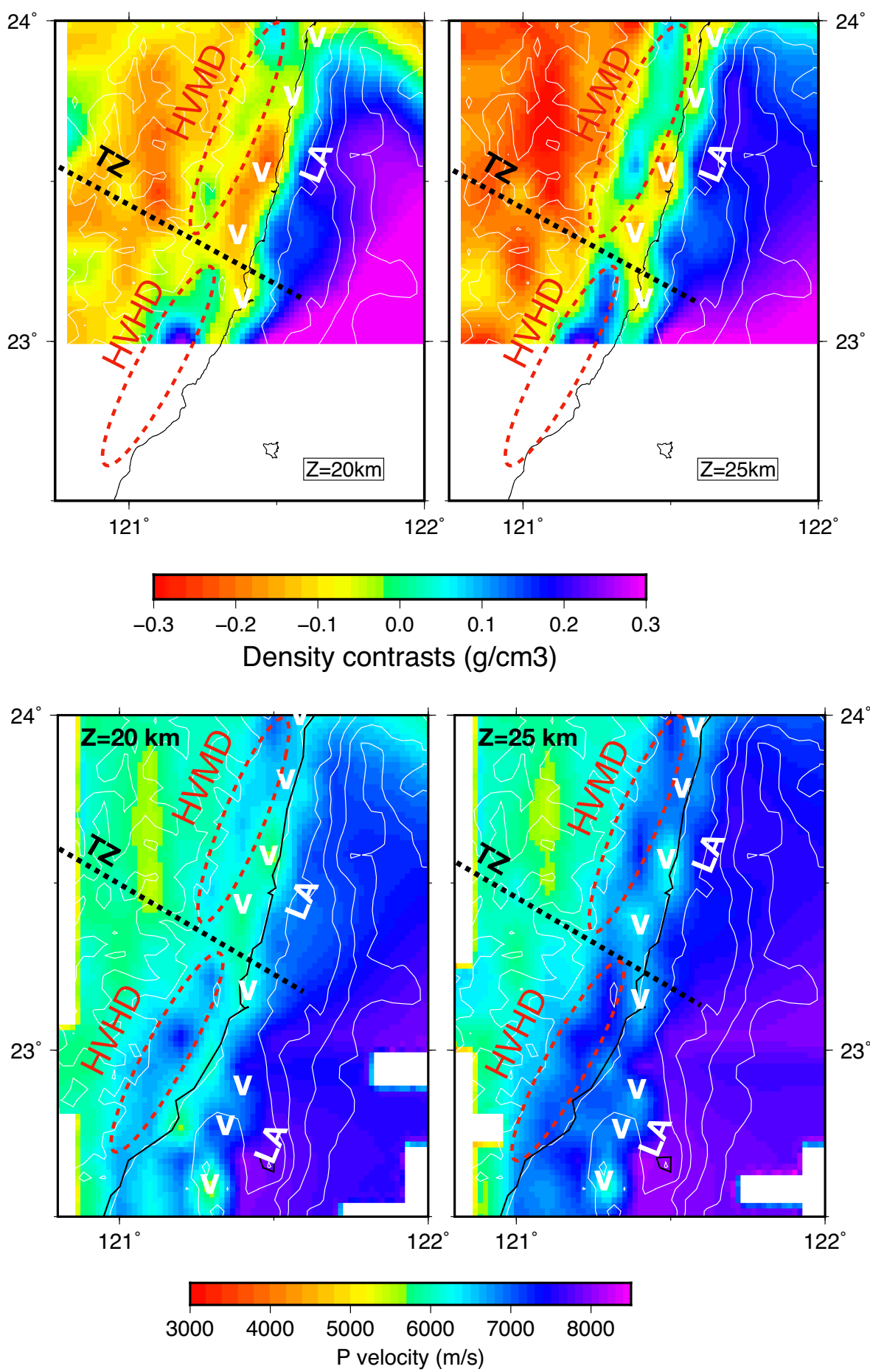

Figure 8. Zooms of both the density contrast and $V p$ models resulting from the sequential joint inversion for two different depths. The annotations are the same than for Figs 6 and 7.

crust and the LA thickened one during the convergence process (Fig. 11). We thus confirm the interpretation of Kim et al. (2006) with an oceanic mantle squeezed at shallow depths in the suture zone between the arc and the orogen in the southern part.

North of $23.5^{\circ} \mathrm{N}$ the LA enters into subduction (Angelier $e t$ al. 1986). The associated LVLD anomalies are sparse, weaker and shifted to the west (Figs 6-8). We infer that the oceanic mantle of the Luzon forearc disappears as the plate sinks. In this case, the high velocity moderate density (Figs 6-8, HVMD label) imaged at 25 down to $40 \mathrm{~km}$ depth below the Longitudinal Valley is no more related to squeezed oceanic mantle (Theunissen et al. 2012b; Lallemand et al. 2013), nor metamorphic rocks (Lin et al. 1998; 


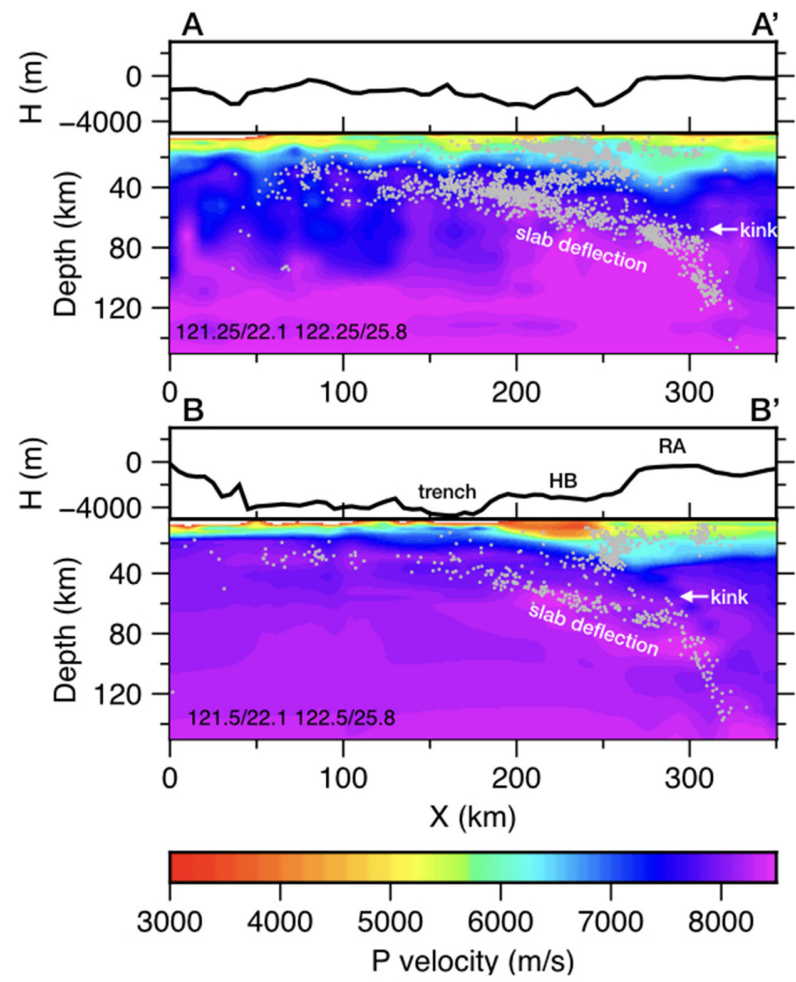

Figure 9. $\mathrm{AA}^{\prime}$ and $\mathrm{BB}$ ' cross-sections along NNE-SSW profiles through the $P$-wave velocity model with associated relocated seismicity (grey dots). The location of sections is indicated on the velocity map at $15 \mathrm{~km}$ depth (Fig. 6). The upper panel represents the topography (vertical exaggeration). The numbers in the panel are the starting and ending points of the profile. HB, Hoping Basin; RA, Ryukyu Arc.

McIntosh et al. 2005). We rather relate it to an asthenosphere infiltration as a result of a slab tearing mechanism (Teng et al. 2000; Lallemand et al. 2001b).

\subsection{Transfer zone}

Our results show that a major segmentation in both velocity and density patterns happens at $\sim 23.5^{\circ} \mathrm{N}$ (Fig. 8). The Moho depth beneath the Central Range is maximal between $23.5^{\circ} \mathrm{N}$ and $24.5^{\circ} \mathrm{N}$ as already observed by Kuo-Chen et al. (2012) but it dramatically shallows south of $23.5^{\circ} \mathrm{N}$ (Fig. 5) along a NW-SE-trending lineament parallel to the relative convergence direction between the EP and PSP plates. This lineament also deflects the surface trace of major thrusts in the Taiwan orogen (Fig. 1), the crustal thickness at depth (Fig. 5), and the axis of the colliding LVA as described by Lallemand et al. (2013) and Huang et al. (2014b). This deflection is observed at the scale of the whole lithosphere (Huang et al. 2014b) (Figs 5-8). We interpret it as a combined effect of the Peikang High (Fig. 1) impingement of the orogen from the west and the southern termination of the EP slab tear in the east (Teng et al. 2000; Lallemand et al. 2001b).

\subsection{Rotation of the northern part of the central range}

As shown in Figs 5-7, the EP slab ends at $24.5^{\circ} \mathrm{N}$, where it meets the PSP (Lallemand et al. 2013, Fig. 5). This pivot zone, modelled by Chemenda et al. (2001), coincides with the pole of a clockwise rotation of $c a .100^{\circ}$ estimated through local GPS variations in the region (Rau et al. 2008). We propose that the collision between the
EP and PSP plates at this location is accommodated through the clockwise rotation of the northern tip of the Central Range. The extrusion of the northern part of the Central Range is facilitated by the westward propagation of the Southern Okinawa Trough rift through the Lishan Fault acting as a weakness zone (Fig. 1). The EW-trending sinistral Choshui strike-slip fault also probably participates to the clockwise rotation (Rau et al. 2008). The rotating block overrides and deflects the subducting PSP, inducing a steep change in the slab geometry, as evidenced by the seismicity distribution (Fig. 9). The clustered seismicity also reflects the brittle deformation due to the overriding plate. Our joint inversion combined with the seismicity relocation show that the change of slab dip angle previously interpreted as the result of the Okinawa basin opening (Wu et al. 2009) can also be due to the overload of the northern Central Range rotating block.

\subsection{Slabs interaction}

The use of density in our inversion allows us to better constrain the EP slab geometries compared with tomography images alone (Figs 9 and 10). North of the transfer zone, the EP slab becomes steeper and is even westward reversed $\left(>90^{\circ}\right)$ north of $24^{\circ} \mathrm{N}$. This extreme bending (Ustaszewski et al. 2012) favours plastic deformation and may allow for a southward propagating slab detachment (Lallemand et al. 2001b). This EP slab break-off also results from (1) the stretching of the plate caused by the downward pull of the oceanic part of the slab versus the buoyancy of continental part of the plate still deforming in the Taiwan orogen and (2) the indentation of the EP slab by the western edge of the PSP. Lin \& Kuo (2016) have simulated the mantle flow related to two opposite-vergent subduction zones in the Taiwan area and concluded that a clockwise toroidal flow beneath Northeast Taiwan occurred as both trenches and slabs retreat. This mantle flow is also consistent with the rotation of the northern CR block. Based on $V p / V s$ structures, Lin et al. (2004) proposed that melting features intrude the lithosphere just north of Hualien, northeast Taiwan. Taking together this bunch of observations, we suggest that the asthenosphere is flowing clockwise beneath northeast Taiwan and part of the flow is invading the EP slab tear (Fig. 11). This process is migrating southward beneath the Longitudinal Valley and explains the amplitude of both velocity and density anomalies we imaged in this study (Figs 5-10). The tearing stops at the TZ, south of which crustal exhumation has been proposed to explain local aseismic behaviour and high heat-flow (Lin 2000). The TZ clearly denotes the limit between two different rheological lithospheric behaviours.

\section{CONCLUSION}

The high-resolution sequential inversion for seismic and density structures in northeastern Taiwan unveils crustal and lithospheric geometrical relationships and their roles in the geodynamics of the Southern Ryukyu and Taiwan areas.

We distinguish two areas of accommodation for the convergence of the EP and PSP plates beneath Taiwan, separated by a NW-SE trending transfer zone parallel to the convergence direction. This transfer zone offsets both crustal and lithospheric structures and delimits major changes in the EP slab geometry and dynamics. South of $23.5^{\circ} \mathrm{N}$, the EP slab gently dips eastwards and the Luzon Arc collision pinches forearc material beneath the Longitudinal Valley. North of the transfer zone, the EP slab dip increases beyond $90^{\circ}$ north of $24^{\circ} \mathrm{N}$. This extreme bending and the presence of a blocked 

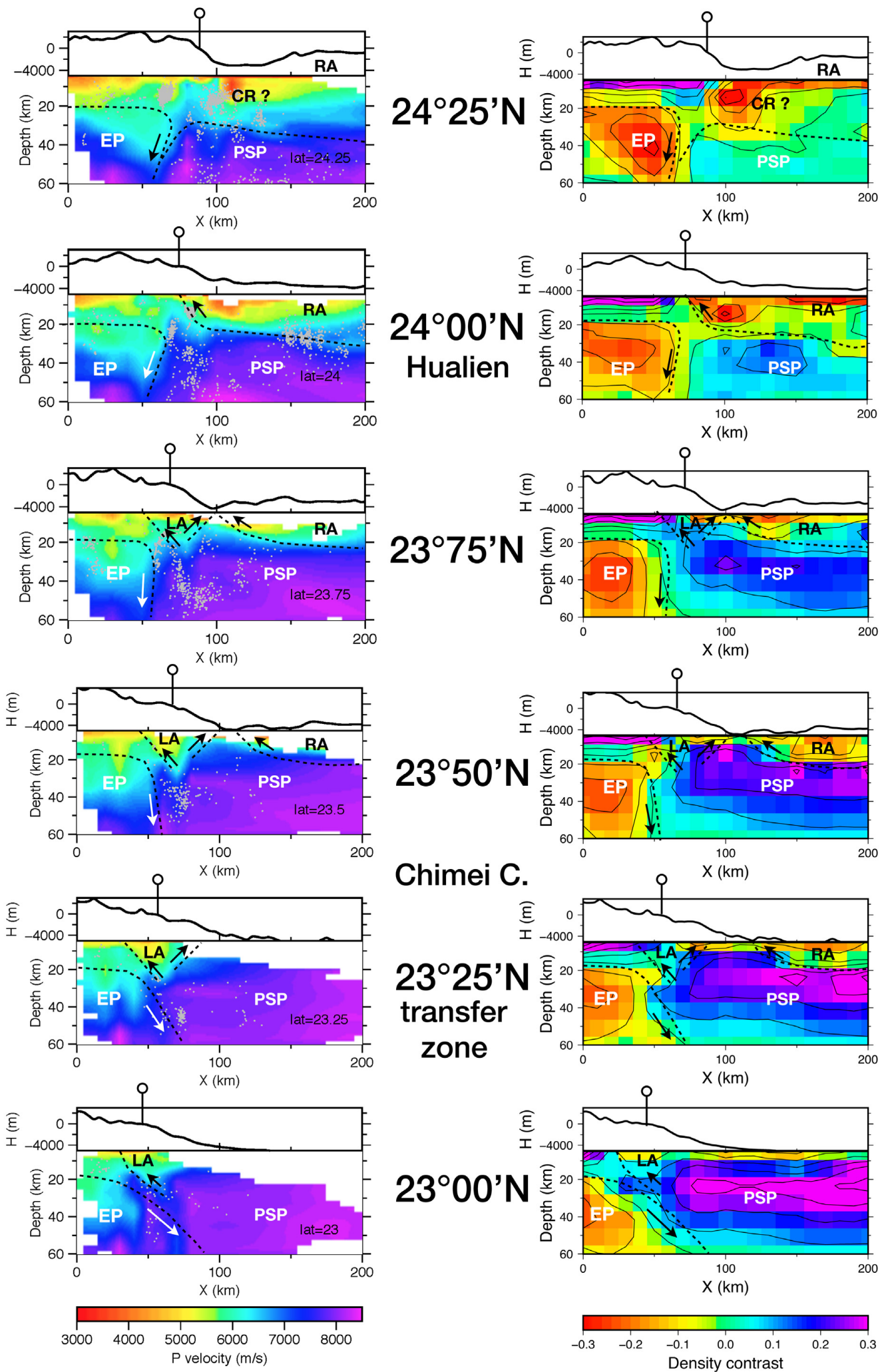

Figure 10. EW cross-sections of the $V p$ model (left-hand panel) and the density contrast (right-hand panel). CR, Central Range extruded northern block; EP, Eurasian Plate; PSP, Philippine Sea Plate; LA, Luzon Arc; RA, Ryukyu Arc. The dashed black lines emphasize the plate boundaries and the arrow indicates relative plate motion. Relocated seismicity is reported as grey dots. Top panels contain the topography with vertical exaggeration. The coastline is indicated by the stylised pin. 


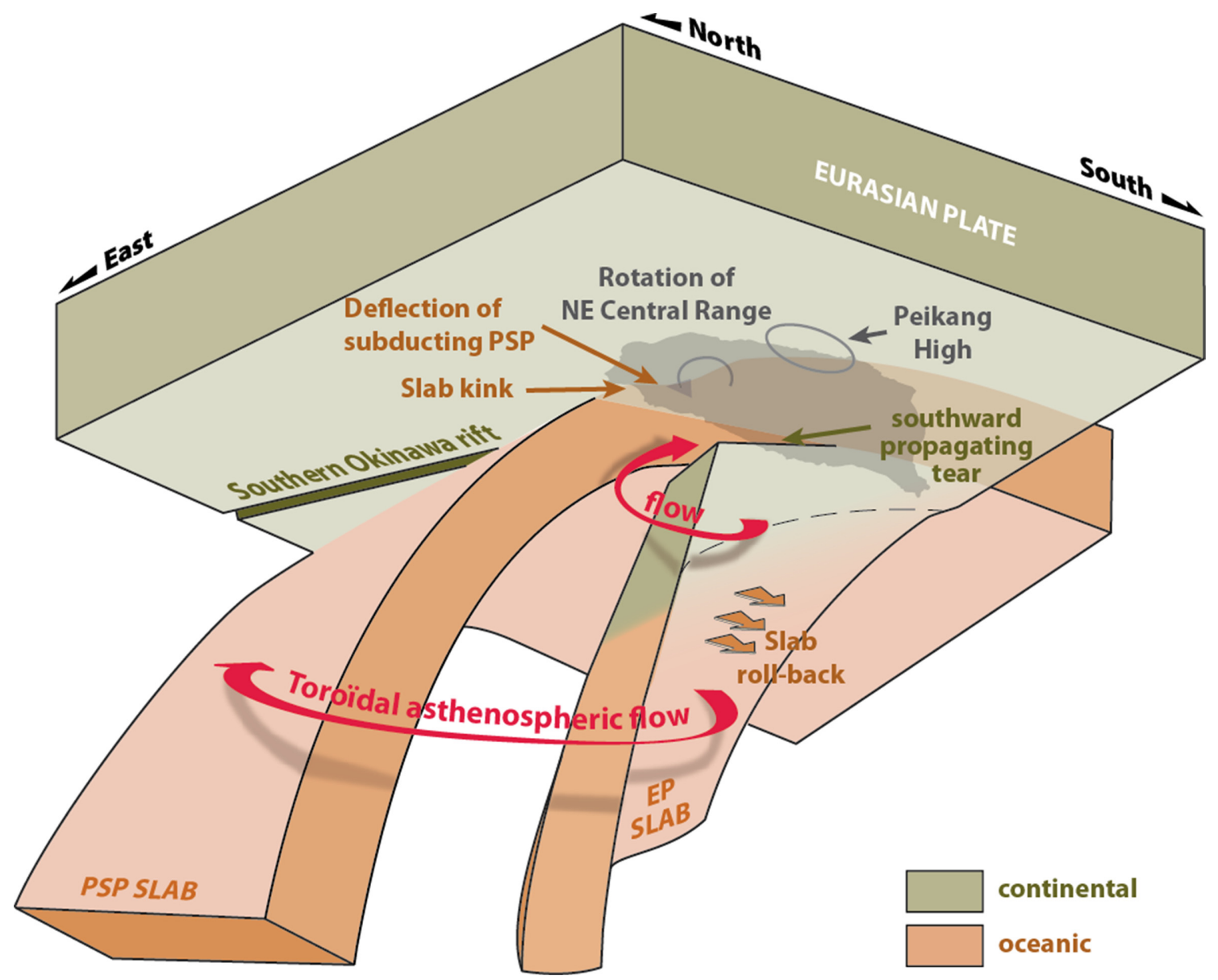

Figure 11. Geodynamic interpretation of lithosphere-asthenosphere interaction at the junction between two orthogonal retreating subduction systems. View is from below towards the southwest. See text for explanation.

zone results in the EP slab tearing, offering the asthenosphere the opportunity to intrude lithospheric material along a narrow corridor. At crustal scale, the deformation is accommodated through stretching and the clockwise rotation of the northern tip of the Central Range. The overload of this thickened crust leads to the deflection of the PSP slab observed in this region and may interact with the EP slab tearing. The indentation of the PSP through the EP results in complex lithospheric accommodation processes and structures.

\section{ACKNOWLEDGEMENTS}

Participation of M. Lopez was supported by ANR grant ANR-12JS06-0004 (CoLiBrEA), and Géosciences Montpellier. This work has been done in the framework of the LIA D3E between CNRSINSU and MOST. The records used in this study were collected from the Central Weather Bureau Seismic Network (CWB) of the Taiwan and from the Japan Meteorological Agency network (JMA). The authors thank the Editor Pr. Huajian Yao and the two reviewers for their comments and suggestions which helped us to improve the original paper.

\section{REFER EN CES}

Angelier, J., 1986. Preface. Geodynamics of the Eurasia-Philippine Sea plate boundary, Tectonophysics, 125, IX-X.
Angelier, J., Barrier, E. \& Chu, H.T., 1986. Plate collision and paleostress trajectories in a fold-thrust belt: the foothills of Taiwan, Tectonophys, 125(1-3), 161-178.

Basuyau, C. \& Tiberi, C., 2011. Imaging lithospheric interfaces and 3D structures using recei- ver functions, gravity and tomography in a common inversion scheme, Comput. Geosci., 37, 1381-1390.

Birch, F., 1961. The velocity of compressional waves in rocks to 10 kilobars: 2., J. geophys. Res., 66(7), 2199-2224.

Blakely, R., 1995. Potential Theory in Gravity and Magnetic Applications, Cambridge University Press.

Chemenda, A.I., Yang, R.K., Konstantinovskaia, E.A. \& Ivanov, G.M., 2001. New results from physical modeling of arc-continent collision in Taiwan: evolutionary model, Tectonophys, 333(1-2), 159-178.

Chou, H.C., Kuo, B.Y., Chiao, L.Y., Zhao, D. \& Hung, S.H., 2009. Tomography of the westernmost Ryukyu subduction zone and the serpentinization of the fore-arc mantle, J. geophys. Res., 114, B12301, doi: 10.1029/2008JB006192.

Christensen, N.I., 1996. Poisson's ratio and crustal seismology, J. geophys. Res., 101(B2), 3139-3156.

Chung, D., 1972. Birch's law: Why is so good?, Science, 177(4045), 261263.

Gautier, S., Latorre, D., Virieux, J., Deschamps, A., Skarpelos, C., Sotiriou, A., Serpetsidaxi, A. \& Tselentis, A., 2006. A new passive tomography of the Aigion area (Gulf of Corinth, Greece) from the 2002 dataset, Pageoph., 163, p431-p453.

Gautier, S., Nolet, G. \& Virieux, J., 2008. Finite-Frequency tomography in a crustal environment: application to the western part of the Gulf of Corinth, Geophys. Prospect., 56(4), 493-503. 
Huang, H.-H., Wu, Y.-M., Song, X., Chang, C.-H., Kuo-Chen, H. \& Lee, S.-J., 2014b. Investigating the lithospheric velocity structures beneath the Taiwan region by nonlinear joint inversion of local and teleseismic P wave data: slab continuity and deflection, Geophys. Res. Lett., 41, doi:10.1002/2014GL061115.

Huang, H.H., Wu, Y.M., Song, X., Chang, C.H., Lee, S.J., Chang, T.M. \& Hsieh, H.H., 2014a. Joint Vp and Vs tomography of Taiwan: implications for subduction-collision orogeny, Earth planet. Sci. Lett., 392, 177-191.

Hwang, C. et al., 2014. New free-air and Bouguer gravity fields of Taiwan from multiple platforms and sensors, Tectonophysics, 611, 83-93.

Julia, J., Ammon, C., Herrmann, R. \& Correig, A., 2000. Joint inversion of receiver function and surface wave dispersion observations, Geophys. $J$. Int., 143, 99-112.

Kao, H. \& Rau, R.-J., 1999. Detailed structures of the subducted Philippine Sea Plate beneath northeast Taiwan: a new type of double seismic zone, J. geophys. Res., 104(B1), 1015-1033.

Kim, K.H., Chiu, J.M., Pujol, J. \& Chen, K.C., 2006. Polarity reversal of active plate boundary and elevated oceanic upper mantle beneath the Collision Suture in Central Eastern Taiwan, Bull. seism. Soc. Am., 96(3), 796-806.

Kim, K.H., Chiu, J.M., Pujol, J., Chen, K.C., Huang, B.S., Yeh, Y.H. \& Shen, P., 2005. Three-dimensional Vp and Vs structural models associated with the active subduction and collision tectonics in the Taiwan region from 3-D seismic tomography, Geophys. J. Int., 162, 204-220.

Kissling, E., Ellsworth, W.L., Eberhart-Phillips, D. \& Kradolfer, U., 1994. Initial reference models in local earthquake tomography, J. geophys. Res., 99(B10), 19635-19646.

Kuo-Chen, H., Wu, F. \& Roecker, S., 2012. Three-dimensional P velocity structures of the lithosphere beneath Taiwan from the analysis of TAIGER and related seismic data sets, Geophys. J. Res., 117, B06306, doi:10.1029/2011JB009108.

Lallemand, S., Font, Y., Bijwaard, H. \& Kao, H., 2001b. New insights on 3-D plates interaction near Taiwan from tomography and tectonic implications, Tectonophysics, 335(3-4), 229-253.

Lallemand, S., Liu, C.-S., Angelier, J. \& Tsai, Y.-B., 2001a. Active subduction and collision in Southeast Asia, Tectonophysics, 333, 1-7.

Lallemand, S., Theunissen, T., Schnürle, P., Lee, C.-S., Liu, C.-S. \& Font, Y., 2013. Indentation of the Philippine Sea Plate by the Eurasia Plate in Taiwan: details from recent marine seismological experiments, Tectonophysics, 594, 60-79.

Lallemand, S.E. \& Tsien, H.-H., 1997. An introduction to active collision in Taiwan, Tectonophys, 274(1-3), 1-4.

Lees, J. \& VanDecar, J., 1991. Seismic tomography constrained by Bouguer gravity anomalies: applications in western Washington, Pure appl. Geophys., 135, 31-52.

Lin, C.-H., 2000. Thermal modeling of continental subduction and exhumation constrained by heat flow and seismicity in Taiwan, Tectonophysics, 324(3), 189-201.

Lin, C.-H., Yeh, Y.-H., Yen, H.-Y., Chen, K.-C., Huang, B.-S., Roecker, S.-W. \& Chiu, J.-M., 1998. Three-dimensional elastic wave velocity structure of the Hualien region of Taiwan: evidence of active crustal exhumation, Tectonics, 17(1), 89-103.

Lines, L., Schultz, A. \& Treitel, S., 1988. Cooperative inversion of geophysical data, Geophysics, 53, 8-20.

Lin, J.-Y., Hsu, S.-K. \& Sibuet, J.-C., 2004. Melting features along the western Ryukyu slab edge (northeast Taiwan): tomographic evidence, $J$. geophys. Res., 109, B12402, doi:10.1029/2004JB003260.

Lin, S.-C. \& Kuo, B.-Y., 2016. Dynamics of the opposite-verging subduction zones in the Taiwan region: insights from numerical models, J. geophys. Res., 121(3), 2174-2192.

Li, Z., Roecker, S., Kim, K., Xu, Y. \& Hao, T., 2014. Moho depth variations in the Taiwan orogeny from joint inversion of seismic arrival time and Bouguer gravity data, Tectonophysics, 632, 151-159.

Lomax, A., Virieux, J., Volant, P. \& Berge-Thierry, C., 2000. Probabilistic Earthquake Location in 3D and Layered Models, pp. 101-134, Springer.
Lo, Y.T., Yen, H.Y. \& Chen, C.R., 2018. Correlation between the Bouguer gravity anomaly and the TAIGER tomography of the Taiwan region, Terr. Atmos. Ocean. Sci., 29(5), 473-483.

Lu, Y.C. \& Malavieille, J., 1994. Oblique convergence, indentation and rotation tectonics in the Taiwan Mountain Belt: Insights from experimental modelling, Earth Planet Sci. Lett., 121, 477-494.

Malavieille, J., Lallemand, S.E., Dominquez, S., Deschamps, A., Lu, C.-Y., Liu, C.-S. \& Schnu"rle, P., 2002. Arc-continent collision in Taiwan: new marine observations and tectonic evolution, in Geology and Geophysics of an Arc-Continent Collision, Taiwan, pp. 187-211, eds Byrne, T.B. \& Liu, C.-S., Geol. Soc. Am. Special Paper, 358, Boulder, Colorado.

Masson, F., Mouyen, M., Hwang, C., Wu, Y.-M., Ponton, F., Lehujeur, M. \& Dorbath, C., 2012. Lithospheric structure of Taiwan from gravity modelling and sequential inversion of seismological and gravity data, Tectonophys, 578, 3-9.

McIntosh, K., Nakamura, Y., Wang, T.K., Shih, R.C., Chen, A. \& Liu, C.S., 2005. Crustal-scale seismic profiles across Taiwan and the western Philippine Sea. Tectonophysics, 401(1-2), 23-54.

Nafe, J.E. \& Drake, C.L., 1963. Physical properties of marine sediments, in The Sea, Vol. 3, pp. 794-815, ed. Hill, M.N., Interscience, New York.

Nolet, G. \& Moser, T.J., 1993. Teleseismic delay times in a 3-D Earth and a new look at the S discrepancy, Geophys. J. Int., 114, 185-195.

Paige, C.C. \& Saunders, M.A., 1982. LSQR: an algorithm for sparse linear equations and sparse least squares, ACM Trans. Math. Softw., 8(1), 43-71.

Parsons, T., Blakely, R. \& Brocher, T., 2001. A simple algorithm for sequentially incorporating gravity observations in seismic traveltime tomography, Int. Geol. Rev., 43, 1073-1086.

Pavlis, G.L. \& Booker, J.R., 1983. A study of the importance of nonlinearitu in the inversion of earthquake arrival time data for velocity structure, $J$. geophys. Res., 88(B6), 5047-5055.

Podvin, P. \& Lecomte, I., 1991. Finite difference computation of travel times in very contrasted velocity models: a massively parallel approach and its associated tools, Geophys. J. Int., 105, 271-284.

Priolo, E. et al., 2012. The Campi Flegrei Blind Test: evaluating the imaging capability of local earthquake tomography in a volcanic area, Int. J. Geophys., 2012, 37, doi:10.1155/2012/505286.

Rau, R.-J., Ching, K.-E., Hu, J.-C. \& Lee, J.-C., 2008. Crustal deformation and block kinematics in transition from collision to subduction: global positioning system measurements in northern Taiwan, 1995-2005, J. geophys. Res., 113, B09404, doi:10.1029/2007JB005414.

Roecker, S.W., Thurber, C. \& McPhee, D., 2004. Joint inversion of gravity and arrival time data from Parkfield New constraints on structure and hypocenter locations near the SAFOD drill site, Geophys. Res. Lett., 31, L12S04, doi:10.1029/2003GL019396

Sibuet, J.-C., Deffontaines, B., Hsu, S.-K., Thareau, N., Le Formal, J.-P. \& Liu, C.-S. the ACT party, 1998. Okinawa trough backarc basin: Early tectonic and magmatic evolution, J. geophys. Res., 103(B12), 30 245-30 267.

Suppe, J., 1984. Kinematics of arc-continent collision, flipping of subduction and back-arc spreading near Taiwan, Mem. Geol. Soc. China, 6, 21-33.

Tarantola, A., 2004. Inverse Problem Theory and Methods for Model Parameter Estimation, Soc. for Industrial and Applied Math.

Teng, S.L., Lee, C.-T., Tsai, Y.B. \& Hsiao, L.-Y., 2000, Slab break off as a mechanism for flipping subduction polarity in Taiwan, Geology, 28(2), $155-158$.

Theunissen, T., Font, Y., Lallemand, S. \& Gautier, S., 2012a. Improvements of the maximum intersection method for 3D absolute earthquake location, Bull. seism. Soc. Am., 102-4, 1764-1785.

Theunissen, T., Lallemand, S., Font, Y., Gautier, S., Lee, C.-S., Liang, W.-T., Wu, F. \& Berthet, T., 2012b. Crustal deformation at the southernmost part of the Ryukyu subduction (East Taiwan) as revealed by new marine seismic experiments, Tectonophysics, 578, 10-30.

Tiberi, C., Diament, M., Déverchère, J., Petit-Mariani, C., Mikhailov, V., Tikhotsky, S. \& Achauer, U., 2003. Deep structure of the Baikal rift zone revealed by joint inversion of gravity and seismology, Geophys. J. Int., 108(B3), 2133, doi:10.1029/2002JB001880. 
Ustaszewski, K., Wu, Y.-M., Suppe, J., Huang, H.-H., Chang, C.-H. \& Carena, S., 2012. Crust-mantle boundaries in the Taiwan-Luzon arccontinent collision system determined from local earthquake tomography and 1D models: implications for the mode of subduction polarity reversal, Tectonophys, 578, 31-49.

Vernant, P., Masson, F., Bayer, R. \& Paul, A., 2002. Sequential inversion of local earthquake traveltimes and gravity anomaly - the example of the Western Alps, Geophys. J. Int., 150, 79-90

Widiwijayanti, C., Tiberi, C., Deplus, C., Diament, M., Mikhailov, V. \& Louat, R., 2004. Geodynamic evolution of the northern Molucca Sea area (Eastern Indonesia) constrained by 3-D gravity field inversion, Tectonophys, 386, 203-222.
Wu, Y., Shyu, J.B., Chang, C., Zhao, L., Nakamura, M. \& Hsu, S., 2009. Improved seismic tomography offshore northeastern Taiwan: implications for subduction and collision processes between Taiwan and the southernmost Ryukyu, Geophys J. Int., 178, $1042-1054$

Wu, Y.-M., Chang, C.-H., Zhao, L., Shyu, J.B.H., Chen, Y.-G., Sieh, K. \& Avouac, J.-P., 2007. Seismic tomography of Taiwan: improved constraints from a dense network of strong motion stations, J. geophys. Res., 112, B08312, doi:10.1029/2007JB004983. 